\title{
Sistem Informasi Rekam Medik Pasien Sebagai Implementasi Big Data Dengan NIK di Pelayanan Kesehatan Kota Tegal
}

\author{
Arif Rakhman ${ }^{1}$, Umriaty $^{2}$, Very Kurnia Bakti ${ }^{3}$, \\ ${ }^{13}$ Prodi D3 Teknik Komputer, Politeknik Harapan Bersama \\ Jl. Mataram No.9, Tegal 52147, e-mail: cakrakirana7@gmail.com \\ ${ }_{2}^{2}$ Prodi D3 Kebidanan, Politeknik Harapan Bersama \\ Jl. Mataram No.9, Tegal 52147, e-mail: umri.midwife@gmail.com
}

\section{ARTICLE INFO}

Article history:

Received 26 October 2020

Received in revised from 26 November 2020

Accepted 04 January 2021

Available online 31 January 2021

\begin{abstract}
ABSTRAK
Kemajuan teknologi kesehatan yang cepat dan akurat semakin menjadi kebutuhan utama para pengambil keputusan. Rumah sakit, klinik, puskesmas sebagai institusi yang menyimpan begitu banyak data juga membutuhkan pengolahan data yang benar dan tepat sehingga dapat disajikan dalam bentuk laporan. Sedangkan untuk menyimpan arsip rekam medis tradisional membutuhkan lahan yang luas dan rawan terkena dampak bencana alam dan kebakaran. Menurut sudut pandang pasien, dokumen fisik rekam medis seperti kartu medik, rontgen, hasil USG, hasil EKG dan lain-lain juga berisiko hilang atau rusak sehingga menjadi masalah. Dengan metode riset \& development Borg and Gall yang dimodifikasi, Metode deskriptif dipergunakan untuk menghimpun kondisi yang ada di lapangan. Metode evaluatif dipergunakan untuk mengevaluasi Sistem Informasi Rekam Medis Pasien di Pelayanan Kesehatan Kota Tegal yang diwujudkan dalam bentuk Aplikasi Implementasi Big Data dengan NIK, melalui evaluasi produk dan proses uji coba tersebut diharapkan dapat diperoleh masukan tentang kelebihan-kelebihan dan kekurangankekurangan dari produk tersebut. Dengan dibuatnya aplikasi rekam medis dapat mempermudah kinerja staff puskesmas dan dokter, serta sistem yang lebih efektif dan efisien dan data NIK sudah teritegrasi dengan sistem online.
\end{abstract}

Kata kunci: Sistem Informasi, Rekam Medik, Big Data, NIK.

\section{Pendahuluan}

Adanya kemajuan teknologi kesehatan, informasi yang cepat dan akurat semakin menjadi kebutuhan utama para pengambil keputusan dengan kata lain informasi merupakan kebutuhan dasar yang diperlukan oleh setiap manajemen untuk melakukan pengambilan keputusan[1]. Rumah sakit, klinik, puskesmas maupun dokter praktek sebagai sebuah institusi yang menyimpan

Received October 26, 2020; Revised November 26, 2020; Accepted January 04, 2021 
begitu banyak data juga memerlukan pengolahan data yang benar dan akurat yang dapat disajikan sedemikian rupa dalam bentuk laporan[2].

Teknologi cloud computing, big data dan Internet of thing (IoT) saat ini menjadi tolak ukur keberadaan revolusi industri 4.0. Informasi yang mudah didapat dan mudah diakses dengan kecepatan sangat tinggi melalui media internet menjadikan masyarakat dapat memperoleh informasi secara real time[3][4]. Infrastruktur pemerintah dibidang teknologi informasi seperti internet saat ini sudah dikembangkan dan tersebar di seluruh pulau Indonesia[5]. Keberadaan KTP Elektronik sebagai implementasi big data sudah mulai merambah ke banyak aspek pelayanan publik. Tentunya hal tersebut sangat memungkinkan e-KTP dengan nomor NIK menjadi kunci bagi sesorang untuk mengakses dan diakses datanya oleh pihak siapa pun yang berkepentingan. Termasuk sebagai kunci identitas rekam medik[6]. Adanya e-KTP dengan didukung teknologi IOT memungkinkan dibangunnya sebuah sistem terintegrasi yang daring, demikian juga dari sisi pasien dapat melakukan pemeriksaan kesehatan dimana pun dengan menyampaikan rekam medik nya melalui NIK yang ada pada e-KTP[7].

Di Kota Tegal hampir semua pelayanan kesehatan telah menggunakan Sistem Informasi Kesehatan seperti Puskesmas, Rumah Sakit dan beberapa Klinik. Sistem informasi kesehatan di Puskesmas dinamakan sistem informasi manajemen puskesmas (SIMPUS) yaitu sebuah sistem Informasi yang terintegrasi dan didesain multi user yang disiapkan untuk menangani keseluruhan proses manajemen puskesmas[8]. SIMPUS ini terdiri atas biodata dan catatan medis pasien dengan menggunakan sistem yang berbasis web[9].

Penelitian yang dilakukan oleh Wimmie Handiwidjojo dengan judul rekam medik elektronik, yang didalamnya berisi tentang sebuah sistem rekam medik elektronik yang hanya dapat diakses pada satu pelayanan kesehatan rumah sakit. Rekam medik tersebut memiliki kelemahan data rekam medik tidak dapat diakses oleh pasien diseluruh pelayan kesehatan yang tersebar dalam satu wilayah[10]. Dengan sistem yang baru dapat mengintegrasikan NIK sehingga penelusuran pasien jadi lebih mudah riwayat penyakit dan juga obatnya.

\section{Metode Penelitian}

\subsection{Metode yang digunakan}

Metode penelitian yang dipergunakan adalah metode penelitian dan pengembangan atau Research \& Development (R\&D). Metode yang dipergunakan meliputi metode deskriptif dan evaluatif. Metode deskriptif dipergunakan untuk menghimpun kondisi yang ada di lapangan. Metode evaluatif dipergunakan untuk mengevaluasi Sistem Informasi Rekam Medis Pasien di Pelayanan Kesehatan Kota Tegal .Dalam pengembangan Sistem Informasi Rekam Medis Pasien sebagai Implementasi Big Data dengan NIK dilakukan dengan prosedur pengembangan model Borg and Gall yang dimodifikasi.

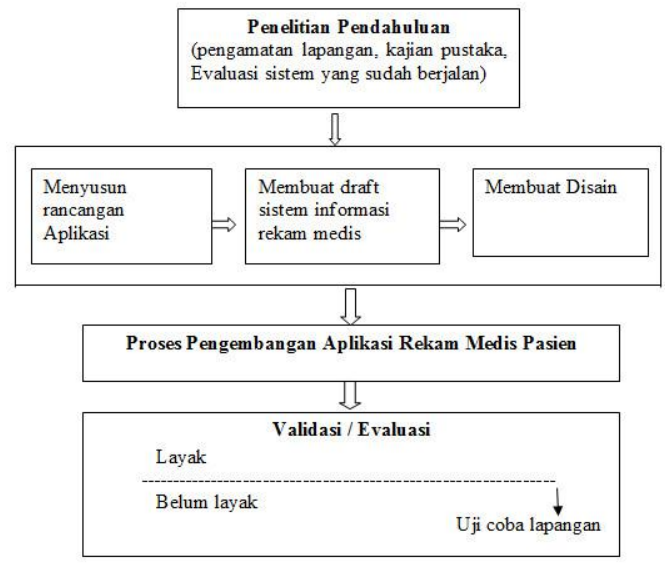

Gambar 1. Bagan Penelitian

TRANSFORMATIKA Vol. 18, No. 2, January 2021: $143-150$ 
Langkah-langkah yang dilakukan pada penelitian ini (1) melakukan pengamatan lapangan, kajian pustaka, evaluasi sistem yang sudah berjalan, (2) Menyusun rancangan aplikasi kemudian membuat draft sistem informasi rekam medis dan membuat desain penelitianya, (3) Proses pengembangan aplikasi rekam medis pasien, (4) Melakukan Validasi dan Evaluasi uji sistem.

\subsection{Teknik Pengumpulan dan Analisis Data}

Untuk mendapatkan data yang benar-benar akurat, relevan, dan valid yang menunjang pembangunan sistem maka penulis mengumpulkan sumber data dengan cara (1)Wawancara yaitu pengumpulan data melalui wawancara secara langsung pada sumber informasi dengan tujuan untuk mendapatkan data yang lebih terinci yang berhubungan dengan data-data yang dibutuhkan, (2) Observasi yaitu Pengumpulan data melalui observasi secara langsung terhadap objek penelitian dengan meninjau secara cermat dan teliti terhadap objek penelitian dan (3)Studi Kepustakaan yaitu Metode pengumpulan data ini dilakukan dengan cara mempelajari buku-buku yang berkaitan dengan obyek yang sedang diteliti. Penelitian kepustakaan ini secara teori sangat membantu di dalam penulisan penelitian ini.

\section{Hasil Perancangan}

\subsection{Perancangan sistem}

Perancangan Sistem Aplikasi Rekam Medis pada Klinik Pratama Harapan Bersama Kota Tegal Terdiri dari Use case diagram, Sequence Diagram, Activity Diagram, Class Diagram.

Tabe.1. Identifikasi Aktor

\begin{tabular}{|c|c|c|c|}
\hline No & Aktor & Nama Use Case & Deskripsi \\
\hline 1. & Administrator & Melakukan Login & $\begin{array}{l}\text { Use case menggambarkan kegiatan } \\
\text { memasukan username dan password } \\
\text { untuk mengakses sistem. }\end{array}$ \\
\hline 2. & Administrator & Melalukan logout & $\begin{array}{l}\text { Use case menggambarkan keluar dari } \\
\text { sisrem }\end{array}$ \\
\hline 3. & Administrator & $\begin{array}{l}\text { Manajemen data } \\
\text { Pasien, data Obat, } \\
\text { data dokter dan data } \\
\text { user. }\end{array}$ & $\begin{array}{l}\text { Use case memasukkan data pasien, data } \\
\text { obat, data dokter serta data user. }\end{array}$ \\
\hline 4. & Administrator & $\begin{array}{l}\text { Manajemen rekam } \\
\text { medis }\end{array}$ & $\begin{array}{l}\text { Use case menggambarkan kegiatan } \\
\text { melakukan proses rekam medis. }\end{array}$ \\
\hline 5. & Administrator & $\begin{array}{l}\text { Melakukan cetak } \\
\text { laporan kunjungan } \\
\text { pasien }\end{array}$ & $\begin{array}{l}\text { Use case menggambarkan cetak laporan } \\
\text { kunjungan pasien. }\end{array}$ \\
\hline 6. & Dokter & Manajemen laporan & $\begin{array}{l}\text { Use case menggambarkan kegiatan } \\
\text { melihat laporan kunjungan pasien. }\end{array}$ \\
\hline 7. & Pasien & Data Rekam Medik & $\begin{array}{l}\text { Use case menggambarkan kegiatan data } \\
\text { periksa }\end{array}$ \\
\hline
\end{tabular}

\subsection{Perancangan Database}

Berikut merupakan relasi dan struktur dari database aplikasi remegal dimana relasi tabel digunakan untuk melakukan perintah join antar tabel. 


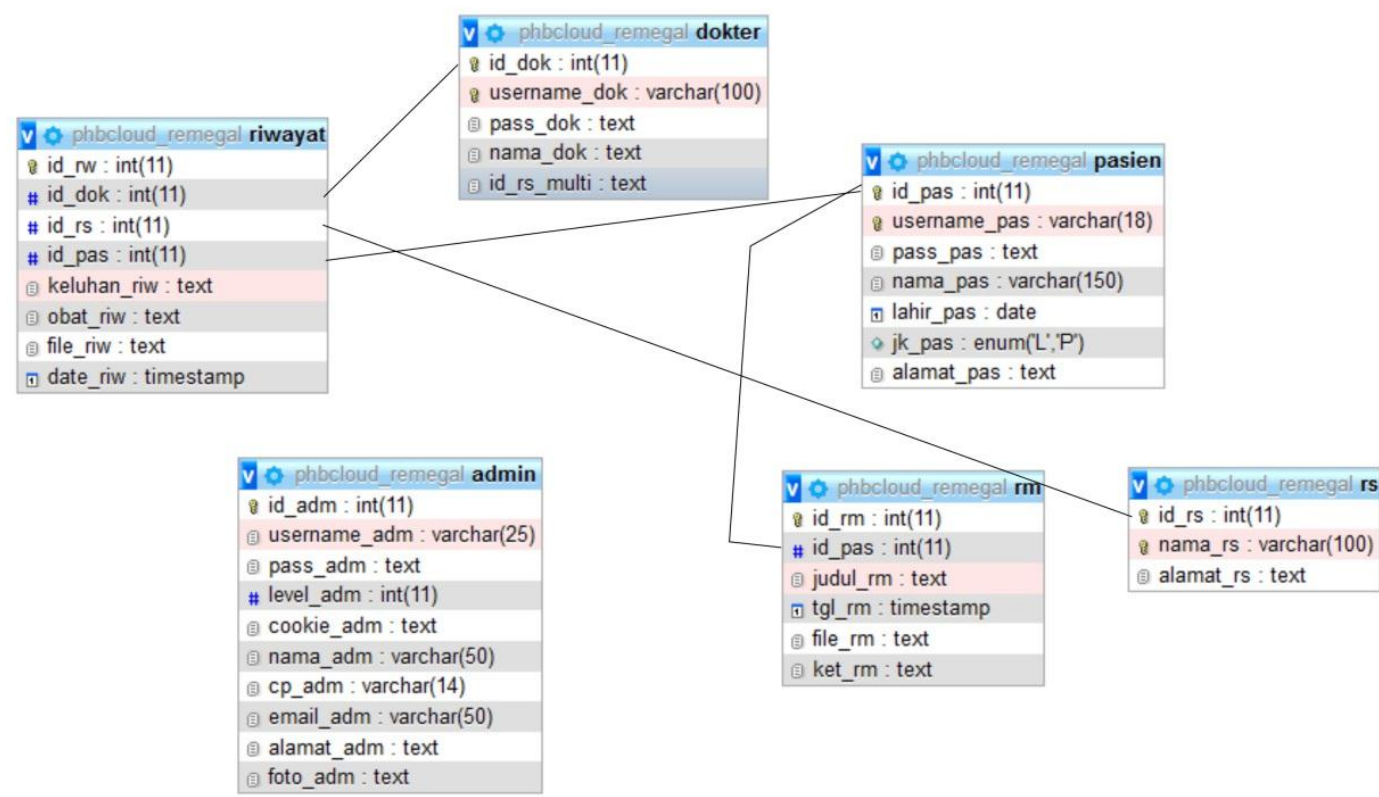

Gambar 2. Bagan relasi aplikasi remegal

Tabel riwayat mempunyai hubungan dengan tabel dokter yaitu di atribut id_dok dan tabel riwayat juga mempunyai hubungan dengan tabel pasien pada atribut id_pas dan tabel riwayat juga mempunyai hubungan tabel rs yaitu pada atribut id_rs. Tabel pasien mempunyai relasi dengan tabel rm pada atribut id_pas.

\subsection{Implementasi sistem}

Tampilan antar muka sistem ini menggambarkan desain yang sebenarnya dari Aplikasi Rekam Medis pada pelayanan kesehatan kota Tegal, ditampilan ini terdapat beberapa halaman, yaitu:

1. Tampilan Halaman Login

Halaman login ini digunakan untuk masuk pasien, dokter dan admin staff pelayanan kesehatan.

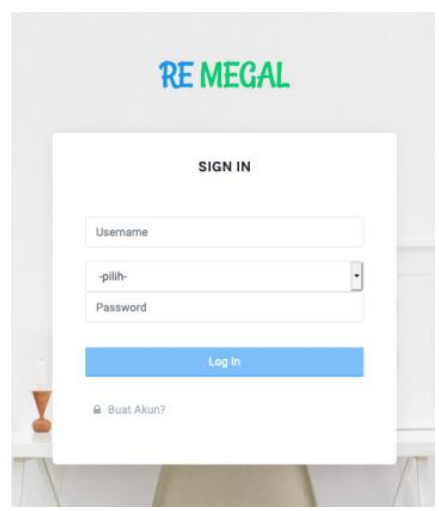

Gambar 3. Tampilan Halaman Login

2. Tampilan Halaman Register

TRANSFORMATIKA Vol. 18, No. 2, January 2021 : 143-150 
Halaman register untuk mendaftar pasien, dokter dan admin staff pelayanan kesehatan jika belum mempunyai akun dan password.

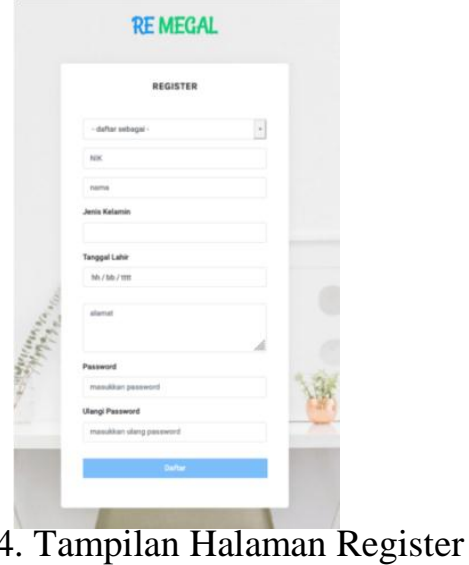

3. Tampilan Laman Password

Gambar 4. Tampilan Halaman Register

Halaman ini digunaka jika pasien, dokter dan admin staff pelayanan lupa pasword atau mau ganti pasword.

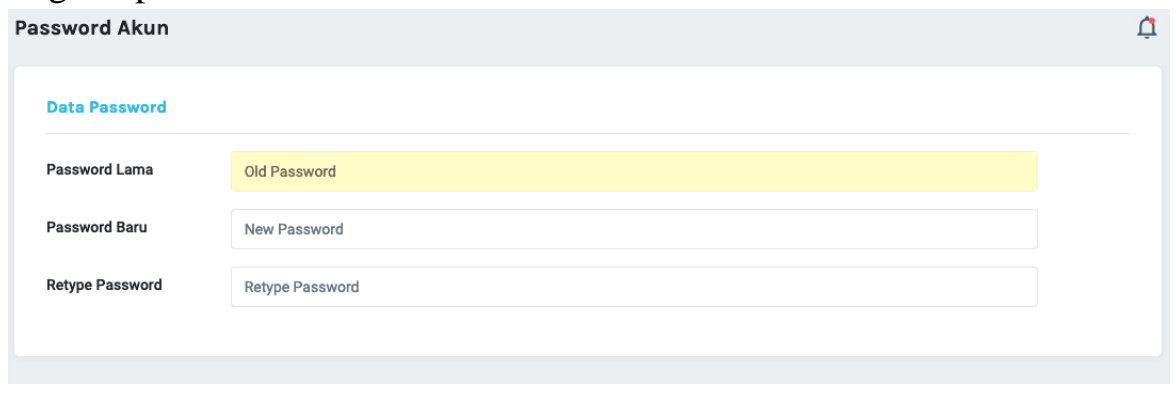

Gambar 5. Tampilan Laman Password

4. Tampilan Laman Menu Admin

Halaman ini berisi tampilan menu admin yang berisi data pasien, dokter, alamat pelayanan kesehatan..

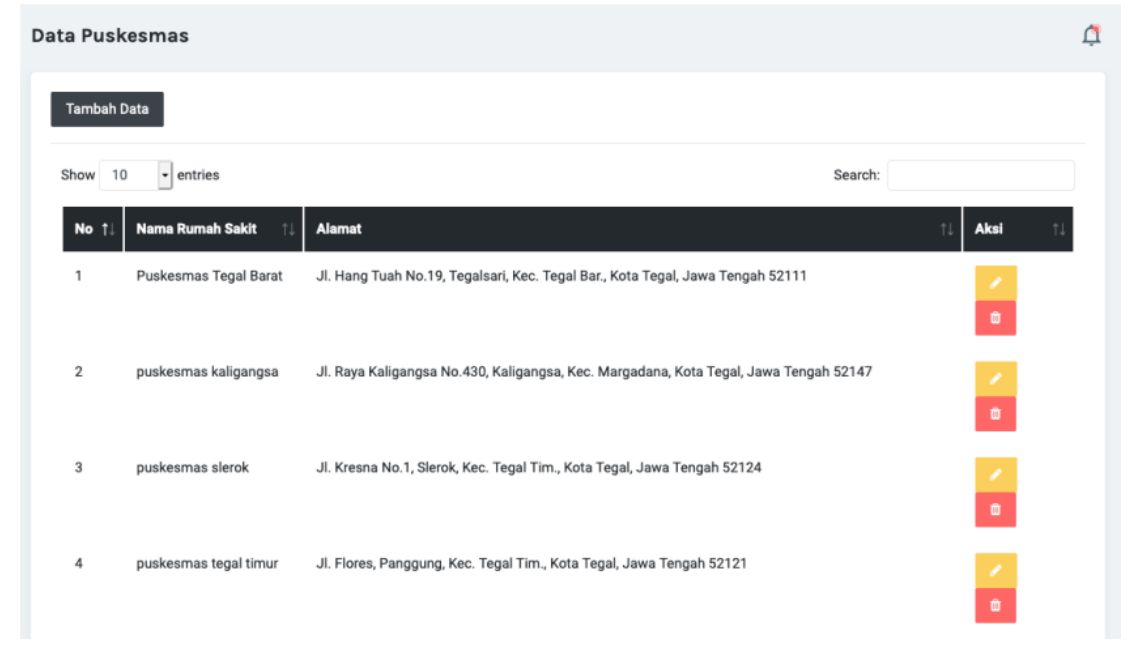

Gambar 6. Tampilan Laman Menu Admin 
5. Tampilan Menu Laman Dokter

Halaman ini berisi tampilan menu dokter yang berisi pasien, alamat pelayanan kesehatan.

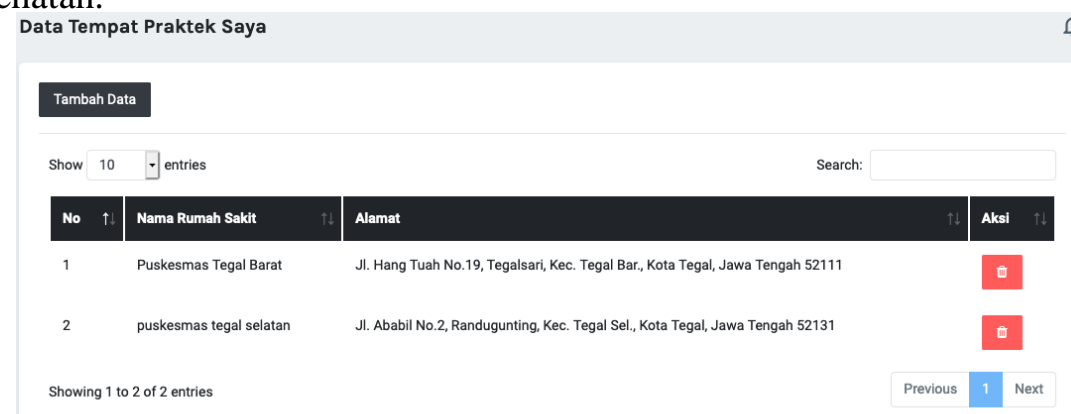

Gambar 7. Tampilan Laman Menu Dokter

6. Tampilan Menu Laman Pasien

Halaman ini berisi menu pasien yang berisi riwayat pasien.

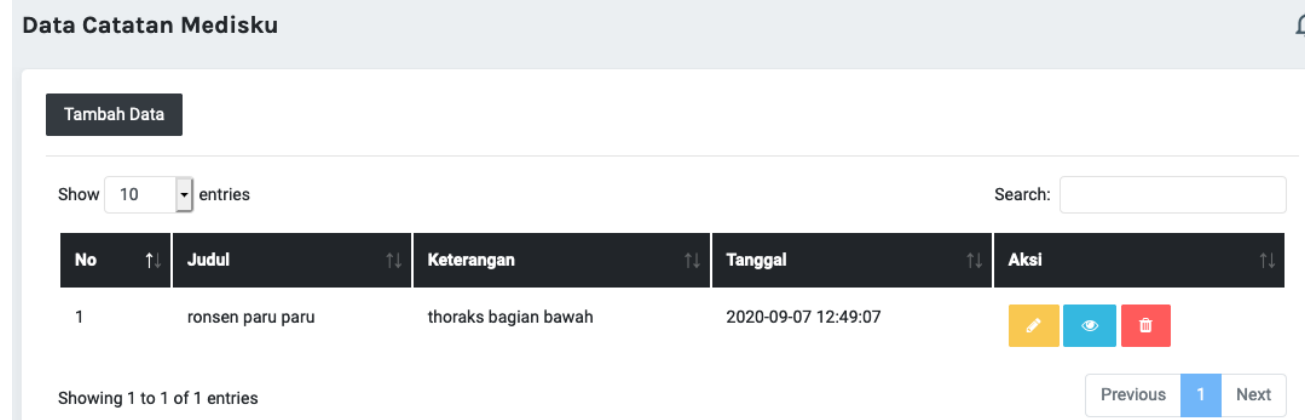

Gambar 8. Tampilan Laman Menu Dokter

\subsection{Hasil Pengujian Blackbox Testing}

Blackbox Testing adalah pengujian yang dilakukan hanya mengamati hasil eksekusi melalui data uji dan memeriksa fungsional dari perangkat lunak.

1) Pengujian Login User

\section{Kasus dan Hasil Uji (Data Benar)}

\begin{tabular}{lll}
\hline Data Masukan & Pengamatan & Kesimpulan \\
\hline Username : 332 & dapat mengisi data login sesuai dengan yang & {$[\sqrt{ }]$ Diterima } \\
Password: 123 & diharapkan & {[] Ditolak } \\
Data Login berupa & Tidak dapat login/ masuk dan menampil-kan & {$[\sqrt{ }]$ Diterima } \\
Username : - & pelaporan sesuai yang diharapkan & {$[$ ] Ditolak } \\
Password : - & &
\end{tabular}

\section{Kasus dan Hasil Uji (Data Salah)}

Username : admin Menampilan pesan "Login Gagal"

$[\sqrt{ }]$ Diterima

Password : 12345

[ ] Ditolak 
2) Tambah data Puskesmas, dokter dan pasien

Kasus dan Hasil Uji (Data Benar)

\begin{tabular}{lll}
\hline Data Masukan & Pengamatan & Kesimpulan \\
\hline $\begin{array}{l}\text { Data Puskesmas } \\
\text { ( Nama, Alamat) }\end{array}$ & Dapat menampilkan form input data puskesmas & {$[\sqrt{ }]$ Diterima } \\
$\begin{array}{l}\text { Pengisian Data } \\
\text { Puskesmas secara }\end{array}$ & $\begin{array}{l}\text { Dapat mengisi masing-masing field dan tersimpan } \\
\text { kedalam database }\end{array}$ & {$[\sqrt{ }]$ Ditolak } \\
$\begin{array}{l}\text { lengkap } \\
\text { Kasus dan Hasil Uji (Data Salah) }\end{array}$ \\
$\begin{array}{ll}\text { Field data puskesmas } \\
\text { tidak di isi. }\end{array}$ & Data Stok Darah tidak ter-simpan kedalam database \\
& & {$[\sqrt{ }]$ Diterima } \\
& {$[$ ] Ditolak }
\end{tabular}

Setelah program dibuat Langkah selanjutnya adalah mengimpletasikan sistem baru tersebut, untuk mendapatkan sistem yang sesuai dengan harapan, maka dibuat rencana implementasi sistem mulai dari testing program, training ,change over dan perawatan.

\section{Testing Program}

Setelah program dibuat, maka dibutuhkan testing aplikasi ini untuk mengetahui apakah program tersebut berjalan sesuai kebutuhan Apotek \& Klinik Pratama Harapan Bersama testing yang dilakukan seperti melakukan input, edit, hapus dan cari data obat, data pasien, data dokter, rekam medis, user, serta melihat dan mencetak riwayat kunjungan pasien. Pada saat testing terdapat sebuah kesalahan atau tidak. Pada saat testing setiap Langkah perlu dicatat sehingga dapat mempermudah perbaikan sistem dan mempermudah dalam pembuatan modul pengoperasian aplikasi rekam medis pada Pelayanan Kesehatan Kota Tegal serta dibuatkan solusi atas masalah tersebut.

2. Training Program

Setelah program di tes Langkah selanjutnya, yaitu training program, training dimaksudkan agar administrator / petugas dapat menggunakan aplikasi ini sesuai prosedur,kegiatan training ini dilakukan sampai petugas benar benar memahami Langkah Langkah penggunaan aplikasi rekam medis ini.

3. Change over

Change over merupakan kegiatan migrasi dari sistem lama kesistem yang baru, karena sistem yang lama sudah tidak efektif dan efesien lagi.metode yang digunakan dalam perpindahan sistem ini menggunakan metode parallel changeover, yaitu sistem lama dan sistem baru dijalankan secara bersamaan selama beberapa waktu. Setelah dipastikan tidak ada kesalahan maka sistem yang sudah teruji ini siap dipakai atau pergantian sistem dilaksanakan demikian seterusnya sampai seluruh aplikasi sistem dapat dipakai.

4. Perawatan

Perawatan adalah sebuah kegiatan untuk menjaga dan memelihara sistem agar sistem tersebut terhindar dari kerusakan dan selalu memiliki kinerja yang maksimal dalam pengoperasian.Perawatan hendaknya dilakukan 1 bulan sekali untuk mengecek peralatan yang digunakan, walaupun tidak ada kerusakan sebaiknya tetap dilakukan pewatan rutin.

\section{Kesimpulan}

Hasil penerapan metode Borg \& Gall dengan dibuatnya aplikasi rekam medis dapat mempermudah kinerja admin staff pelayanan kesehatan dan dokter, serta sistem yang lebih efektif dan efisien dan data NIK sudah teritegrasi dengan sistem online. Di sisi pasien, dokumen 
fisik rekam medis seperti kartu medik, rontgen, hasil USG, hasil EKG dan lain-lain juga sudah tidak takut berisiko hilang atau rusak karena sudah tercatat disistem yang terintegrasi yang baik.

\section{References}

[1] N. Fanny, "Penerapan Model Hot Fit pada Evaluasi Sistem Informasi Keselamatan dan Kesehatan Kerja di RSUD Dr. Moewardi," MEDIA Kesehat. Masy. Indones., vol. 18, no. $1,2019$.

[2] H. N. Putra, "Analisis Pelaksanaan Sistem E-Puskesmas Dengan Menggunakan Metode Pieces Di Puskesmas Pemancungan Padang Tahun 2018," Ensiklopedia J., vol. 1, no. 1, pp. 63-69, 2018.

[3] B. Maryanto, "Big Data dan Pemanfaatannya dalam Berbagai Sektor," Media Inform., vol. 16, no. 2, pp. 17-18, 2017.

[4] R. Brundin-Mather et al., "Secondary EMR data for quality improvement and research: a comparison of manual and electronic data collection from an integrated critical care electronic medical record system," J. Crit. Care, vol. 47, pp. 295-301, 2018.

[5] A. E. Pramono, N. Rokhman, and N. Nuryati, "Telaah Input Data Sistem Informasi Kesehatan di Puskesmas Gondokusuman II Kota Yogyakarta," J. Kesehat. Vokasional, vol. 3, no. 1, pp. 44-52, 2018.

[6] F. Hakam, "Pelatihan Manajemen Rekam Medis Sesuai Dengan Standar Pedoman Penyelenggaraan Dan Prosedur Rekam Medis Di Puskesmas Kecamatan Weru Kabupaten Sukoharjo," J. Manaj. Inf. dan Adm. Kesehat., vol. 1, no. 02, 2018.

[7] P. Margiluruswati, "Analisis Ketepatan Waktu Tunggu Pelayanan Resep Pasien JKN dengan Standar Pelayaan Minimal (SPM) Rumah Sakit," J. Manaj. Kesehat. Yayasan RS. Dr. Soetomo, vol. 3, no. 2, pp. 238-248, 2017.

[8] A. N. Cahyanti and B. E. Purnama, "Pembangunan Sistem Informasi Manajemen Puskesmas Pakis Baru Nawangan," Speed-Sentra Penelit. Eng. dan Edukasi, vol. 4, no. 4, 2017.

[9] J. S.-S. N. Mandiri, "Sistem Informasi Pelayanan Puskesmas Berbasis Web," Indones. J. Softw. Eng., vol. 2, no. 1, 2016.

[10] W. Handiwidjojo, "Rekam medis elektronik," J. Eksplor. Karya Sist. Inf. dan Sains, vol. 2, no. 1, 2015.

TRANSFORMATIKA Vol. 18, No. 2, January 2021: 143-150 